\title{
Sol-gel Synthesis and Characterization of Lithium and Cerium Codoped Perovskite
}

\author{
Katarina Mužina ${ }^{1}$, Marija Tkalčević ${ }^{2}$ Filip Brleković ${ }^{1}$, Ivana Katarina Munda ${ }^{1}$, Vilko \\ Mandić $^{1}$, Juraj Šipušić ${ }^{1}$, Stanislav Kurajica ${ }^{1}$ \\ 1. Faculty of Chemical Engineering and Technology, University of Zagreb, Marulićev trg 19, Zagreb, Croatia \\ 2. Division of Materials Physics, Ruđer Bošković Institute, Bijenička 54, Zagreb, Croatia
}

E-mail: kmuzina@fkit.hr

Received: 17 March 2020; Accepted: 16 April 2020; Available online: 30 April 2020

\begin{abstract}
Perovskites are an important group of ceramic materials with a structural formula $\mathrm{ABO}_{3}$ and wide array of potential applications in electronics, superconductors, catalysis, etc. CaTiO3, by which the whole group was named for, is particularly significant due to its use in catalysis, but its photocatalytic activity is limited by a large band gap value $(\sim 3.5 \mathrm{eV})$. A possible solution is the substitution of A and B cations with foreign cations which causes the alteration of properties, including photocatalytic efficiency. The aim of this work was the sol-gel synthesis of lithium and cerium codoped $\mathrm{CaTiO}$, characterization of the prepared gel and ceramics obtained by its thermal treatment. Samples of codoped perovskite, $\mathrm{Ca}_{1-\mathrm{x}} \mathrm{Li}_{\mathrm{x}} \mathrm{Ce}_{\mathrm{x}} \mathrm{TiO}_{3}$, where $\mathrm{x}=0,0.01,0.02,0.03$ and 0.04, were prepared and characterized using powder X-ray diffraction (XRD), Fourier transformed infrared spectroscopy (FTIR), differential thermal and thermo-gravimetric analysis (DTA-TGA), scanning electron microscopy (SEM) and energy-dispersive X-ray spectroscopy (EDS). Photocatalytic activity was evaluated through the study of methylene blue photocatalytic degradation. XRD analysis showed that the prepared samples consisted of calcium nitrate and titanium chelate. In accordance with the established thermal evolution path, all samples were thermally treated at $500{ }^{\circ} \mathrm{C}$ for 2 hours. Beside perovskite, $\mathrm{Ca}_{2} \mathrm{Ti}_{2} \mathrm{O}_{6}$ appeared as a secondary phase in all thermally treated samples. SEM analysis of thermally treated samples showed the presence of agglomerates of irregular morphology and the decrease of primary particles size with the increase of dopants concentration. The sample with $\mathrm{x}=0.04$ showed an increased photocatalytic activity.
\end{abstract}

Keywords: Perovskite; Codoping; Sol-gel method; Photocatalysis.

\section{Introduction}

New challenges set by the vision of sustainable future necessitate a pursuit for new or functionalized materials. Perovskites are an interesting group of ceramic materials which might be a bridge to that future [1]. The first know perovskite material or the perovskite, by which the entire group of materials sharing its structure got their name, is calcium titanate $\mathrm{CaTiO}_{3}$ [2]. Perovskites are semiconducting materials with a general formula of $\mathrm{ABX}_{3}$, where A represents the bigger metal ion (alkaline or rare earth ion), $\mathrm{B}$ represents the smaller transition metal cation, $\mathrm{X}$ is an anionic group, usually $\mathrm{O}_{2}{ }^{-}$or in halide perovskite structures $\mathrm{Cl}^{-}, \mathrm{Br}^{-}, \mathrm{F}^{-}$or $\mathrm{I}^{-}[3]$. The ideal perovskite material has a cubic structure with space group Pm3m. In this kind of structure coordination of B cation is 6-fold and A cation is 12-fold cuboctahedral, where A ion is surrounded by $\mathrm{X}$ anion octahedrons [4]. Most of the perovskites deviate from the ideal cubic structure and possess distorted cubic, orthorhombic, rhombohedral, tetragonal or hexagonal structures. Due to their diverse structural properties such as lattice defects, the amount of nonstoichiometric oxygen ( $\mathrm{X}$ anion) and unusual oxidation states, these materials have a wide range of possible applications [5]. Some of these applications include catalysis and photocatalysis, solar cells, piezoelectric components, superconductors and many more [6]. One of the most prominent properties of perovskites is the possibility of extensive modifications of their composition. Partial substitution of A or B cations called doping or codoping, when one of the cations is simultaneously substituted with two different cations, results in enhancement of different properties such as catalytic activity, compatibility, stability and conductivity [7]. More than $90 \%$ of elements can be embedded into the lattice of perovskites, which can result in the change of symmetry and composition, as well as creating cation and oxygen vacancies [4]. Perovskite optical properties, namely high efficiency in sunlight harvesting, remarkable charge carrier generation/transfer capabilities and interesting photoluminescence quantum yield, grant them a special place in engineering and development of photovoltaics and in photocatalysis. Consequently, application in photocatalysis is broad and involves synthesis of valuable organic compounds, degradation of organic water pollutants and energy production by water splitting [8]. Waste 
water treatment with semiconductors as photocatalysts falls into the domain of advanced oxidation processes, which refers to processes where very strong chemical oxidants are generated (hydroxyl and superoxide radicals) [9]. Such reactions start with semiconductors absorbing light photons on their surface, which induces the generation of electron-hole pairs that promote wanted reactions [10]. A number of approaches for the preparation of semiconductor photocatalysts are available, such as thermal decomposition method, combustion synthesis, hydrothermal and solvothermal methods, sol-gel method etc. The sol-gel method is a well investigated and elaborated synthesis method of metal oxides and mixed metal oxides. To reach the final metal oxide product, this method undergoes 3 basic steps: hydrolysis, condensation and drying. The first step is the hydrolysis of the metal precursors and the formation of metal hydroxide solution. This induces the condensation of the metal hydroxide sol and the hydrolysis and condensation processes continue simultaneously. In the end a three-dimensional gel is formed. The obtained gels can be dried in atmospheric conditions, which produces xerogels or if dried in supercritical conditions, aerogels. If the reaction occurs in water as the reaction medium and supplier of oxygen, the method is known as aqueous sol-gel. This kind of sol-gel method is somewhat easier and well known; whereas reactions conducted in non-water reaction media or non-aqeous sol-gel have a source of oxygen from different organic solvents. Non-aqueous sol-gel reactions are more complicated and less researched [11]. As already mentioned, the perovskite or calcium titanate is a perovskite material composed of widely available and cheap elements, it has a stable orthorhombic structure with poor optical properties due to a wide band gap of closely 3.6 $\mathrm{eV}$, which limits its possibilities and usage compared to its availability. In this work the improvement of calcium titanate photocatalytical properties by codoping with lithium and cerium by sol-gel method has been carried out [2].

\section{Experimental}

In a $200 \mathrm{ml}$ flask $0.1 \mathrm{~mol}$ (13.014 g) of chelating agent, ethyl acetoacetate, $\mathrm{C}_{6} \mathrm{H}_{10} \mathrm{O}_{3}$ (Fluka), was mixed with

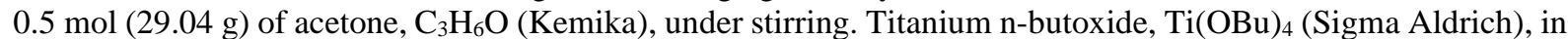
amount of $0.1 \mathrm{~mol}$ (34.032 g) was added to the solution using a syringe. In another flask $0.1 \mathrm{~mol}$ (23.615 g) of calcium nitrate tetrahydrate, $\mathrm{Ca}\left(\mathrm{NO}_{3}\right)_{2} \times 4 \mathrm{H}_{2} \mathrm{O}$ (Kemika), was dissolved in $0.5 \mathrm{~mol}(29.04 \mathrm{~g})$ of acetone under stirring. Second mixture was dropwise added to the first to achieve the molar ratio of 1:1 for Ti and Ca. The solution was magnetically stirred at room temperature for $24 \mathrm{~h}$ and poured into a wide Petri dish in order to enable the gelation to occur. After 7 days the dried gel was grinded and the obtained powder stored in a glass container. Four more syntheses, where part of calcium has been replaced with lithium and cerium, were accomplished in the same manner. As a precursors of lithium and cerium lithium nitrate trihidrate, $\mathrm{LiNO}_{3} \times 3 \mathrm{H}_{2} \mathrm{O}$ (Karlo Erba), and cerium nitrate hexahydrate, $\mathrm{Ce}\left(\mathrm{NO}_{3}\right)_{3} \times 6 \mathrm{H}_{2} \mathrm{O}$ (Merck), were used. Appropriate amounts of lithium and cerium precursors were dissolved in acetone together with the calcium precursor. In such manner five samples with potential composition of $\left(\mathrm{Li}_{\mathrm{X}} \mathrm{Ce}_{\mathrm{X}} \mathrm{Ca}_{1-2 \mathrm{X}} \mathrm{TiO}_{3}\right)$ were prepared.

The powder X-ray diffraction (XRD) was accomplished using Shimadzu diffractometer XRD 6000 with CuK $\alpha$ radiation. Data were collected between 5 and $65^{\circ} 2 \theta$, in a step scan mode with steps of $0.02^{\circ}$ and counting time of $0.6 \mathrm{~s}$.

IR spectra were acquired using the Fourier transform infrared spectrometer Bruker Vertex 70 in ATR (attenuated total reflectance) mode. The samples were pressed on a diamond and the absorbance data were collected between 400 and $4000 \mathrm{~cm}^{-1}$ with spectral resolution of $1 \mathrm{~cm}^{-1}$ and 32 scans.

DTA-TGA thermal analysis was made using Netsch STA 409C. For the thermal analysis $~ 50$ mg of material were placed in Pt crucibles and heated at a rate of $10{ }^{\circ} \mathrm{C} \mathrm{min}-1$ in a synthetic air flow of $30 \mathrm{~cm}^{3} \mathrm{~min}^{-1}$. $\alpha$-alumina was used as a reference.

The morphologies of the prepared powders were investigated with Tescan Vega 3 scanning electron microscope operating at $30 \mathrm{kV}$. Samples for SEM characterization were fixed on a sample holder using double-sided carbon conductive tape and then coated using Quorum SC 7620 sputter coater.

The photocatalytic activity of prepared samples was determined by studying the degradation of methylene blue (MB) as a model compound. Borosilicate cylindrical glass vessel with $100 \mathrm{~mm}$ diameter and $120 \mathrm{~mm}$ height was used as a photocatalytic reactor. A quartz glass tube with a lamp inside was placed axially in the center of the vessel. Pen Ray lamp (UVP Products Cat. No. 90-0012-01), with radiation wavelength $254 \mathrm{~nm}$ and emission intensity of $2 \mathrm{~mW} \mathrm{~cm}^{-2}$, was used as a UV source. $500 \mathrm{~cm}^{3}$ of $14 \mathrm{ppm}$ methylene blue aqueous solution containing $26 \mathrm{mg}$ of catalyst were left stirring at $300 \mathrm{rpm}$ in the dark for $30 \mathrm{~min}$ before switching on the UV lamp in order to achieve a balance of adsorption and desorption of molecules from the surface of the catalyst. The photodegradation experiments were carried out at room temperature $\left(25^{\circ} \mathrm{C}\right)$. Aliquots of $4 \mathrm{~cm}^{3}$ were withdrawn from the mixture by a syringe at regular intervals of $30 \mathrm{~min}$. The first aliquot was withdrawn from the mixture before the commencement of irradiation. The photodegradation was monitored with a UV-Vis Varian, Cary $1 \mathrm{E}$ spectrophotometer. Spectra were acquired and intensity of the main methylene blue absorption band at $\sim 660 \mathrm{~nm}$ measured. The discoloration ratio was calculated as a ratio between absorbance after the measurement interval and 
absorbance prior to irradiation. The degradation of the substance was depicted as discoloration ratio as a function of the irradiation time.

\section{Results and discussion}

XRD patterns of the prepared samples with various amounts of dopants are shown in Fig. 1a. Instead of an amorphous gel, samples of crystalline nature were obtained as evidenced by the sharp peaks. The diffraction angles observed are in agreement with calcium nitrate tetrahydrate, $\mathrm{Ca}\left(\mathrm{NO}_{3}\right)_{2} \times 4 \mathrm{H}_{2} \mathrm{O}$, ICDD PDF No. 26-1406. The variations in peak intensity are most likely due to poor statistics. FTIR spectra of the prepared samples are shown in Fig. 1b. Spectrum of calcium nitrate tetrahydrate was added for comparison, spectra of cerium and lithium nitrates are quite similar to this one. As can be seen, the majority of the bands (at 1635, 1420, 1310, 1045, 815, 745 and $715 \mathrm{~cm}^{-1}$ ) are due to nitrates. Wide band between 3700 and $3000 \mathrm{~cm}^{-1}$ is due to $\mathrm{OH}$ stretching vibrations in water, free or coordinately bound, or as hydroxyl ions [12]. The remaining small bands located at 1525 and $1275 \mathrm{~cm}^{-1}$ could be attributed to the vibration of six membered ring of the titanium-etil acetoacetate complex [12]. The other characteristic chelate absorption band at $1610 \mathrm{~cm}^{-1}$ is overlapped with one of the nitrate bands. The band at $1170 \mathrm{~cm}^{-1}$ is typical for esters [13]. Barely visible absorption bands in the region of $2980-2850 \mathrm{~cm}^{-1}$ are due to $\mathrm{C}-\mathrm{H}$ stretching vibrations. Same as XRD, FTIR spectra showed no significant differences, except for the water bands which is probably due to slight differences in advancement of the drying process.
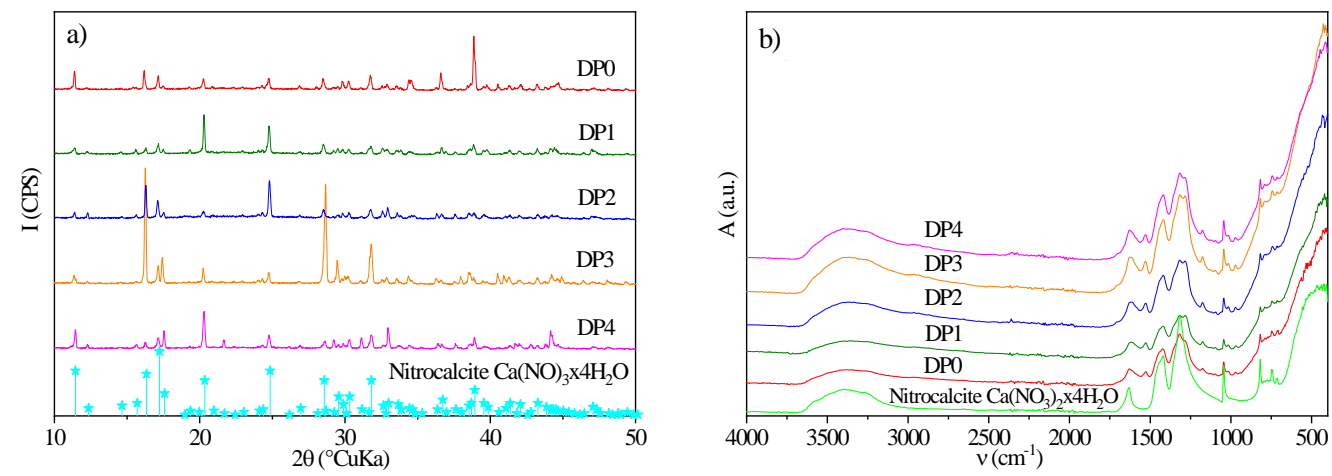

Figure 1. XRD patterns (a) and FTIR spectra (b) of the prepared samples.
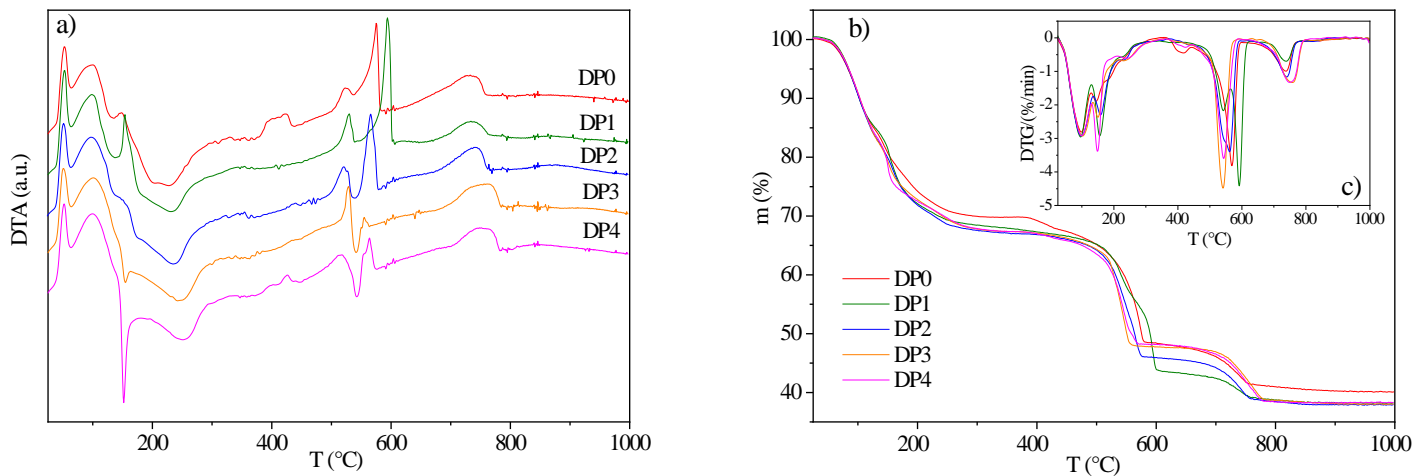

Figure 2. DTA (a), TGA (b) and DTG (c) curves of the prepared samples.

DTA, TGA and DTG curves are shown in Fig. 2. DTA curves (Fig. 2a) exhibit three groups of major peaks. The first group consists of endothermal peaks centered at $\sim 55, \sim 100$ and $150{ }^{\circ} \mathrm{C}$, where later are partially overlapped with exothermal peaks (clearly visible only for samples DP3 and DP4) centered in the same temperature interval. The first group ends with exothermal peaks centered between 230 and $250{ }^{\circ} \mathrm{C}$. On DTA curves of samples DP0 and DP4 two partially overlapped endothermal peaks in a range between 370 and $440{ }^{\circ} \mathrm{C}$ could clearly be observed. The second group is a combination of exothermal and endothermal peaks between 450 and $610^{\circ} \mathrm{C}$. Finally, endothermal peak between 700 and $800{ }^{\circ} \mathrm{C}$ could be observed. TGA curves (Fig. 2b) show major mass losses in three temperature intervals, which are roughly as follows: $30 \%$ from room temperature to $300{ }^{\circ} \mathrm{C}, 20 \%$ from 300 to $600^{\circ} \mathrm{C}$ and $10 \%$ from 600 to $800^{\circ} \mathrm{C}$. DTG curves (Fig. 2c) reveal that three mass loss processes occur in the first interval, centered at approximately 100 and $150{ }^{\circ} \mathrm{C}$ and between 230 and $250{ }^{\circ} \mathrm{C}$. Small 
mass loss between 200 to $300{ }^{\circ} \mathrm{C}$ could be observed in samples DP0 and DP4. One, or for some samples two mass losses are visible in the second interval and one in the third interval.

In order to shed some light on the thermal evolution of the prepared samples, samples DP0 and DP4 were quenched from different temperatures and the obtained samples were subtracted to XRD and FTIR analyses (Figs. 3 and 4). Thermal treatment has been accomplished in a box furnace so some differences in temperatures registered in the course of DTA/TGA analysis and thermal treatment have to be acknowledged. Box furnace has inferior temperature measurement and regulation, certain temperature gradient and atmosphere of static air.

Fig 3a shows XRD patterns of sample DP0 quenched from various temperatures. As can be observed, calcium nitrate tetrahydrate decomposes at temperatures between 100 and $200{ }^{\circ} \mathrm{C}$ yielding with anhydrous calcium nitrate, $\mathrm{Ca}\left(\mathrm{NO}_{3}\right)_{2}$, ICDD PDF No. 7-204. Nitrate is stable until $400-500{ }^{\circ} \mathrm{C}$ where its diffraction peaks disappear, while those due to perovskite, $\mathrm{CaTiO}_{3}$, (ICDD PDF No. 89-6949) appear. Beside perovskite as the main phase weak diffraction peaks of lime, $\mathrm{CaO}$ (ICDD PDF No. 82-1690) and anatase, $\mathrm{TiO}_{2}$ (ICDD PDF No. 89-4921) could be observed. In the sample quenched from $800{ }^{\circ} \mathrm{C}$ phase transformation of anatase to rutile is evidenced by the disappearance of anatase and the appearance of rutile (ICDD PDF No. 89-4920) peaks.

Fig 3b shows FTIR spectra of the sample DP0 quenched from various temperatures. As can be observed, spectrum of the sample quenched from $100^{\circ} \mathrm{C}$ is not particularly different from the as-prepared sample (denoted as 25). On the other hand, in the spectrum of the sample quenched from $200{ }^{\circ} \mathrm{C}$ bands attributed to chelate (1525 and $1275 \mathrm{~cm}^{-1}$ ) disappear completely. Nitrate bands are still present until the sample quenched from $500{ }^{\circ} \mathrm{C}$. The peaks at 430 and $555 \mathrm{~cm}^{-1}$ are due the stretching vibration of Ti-O and bridging stretching modes of Ti-O-Ti, related to $\mathrm{TiO}_{6}$ octahedra in perovskite [14]. Weak bands observed at 1460 and $1410 \mathrm{~cm}^{-1}$ were attributed to carboxylic groups [15]. The calcium carbonate present in the samples arose from CaO since FTIR measurements were taken slightly later than XRD analyses.
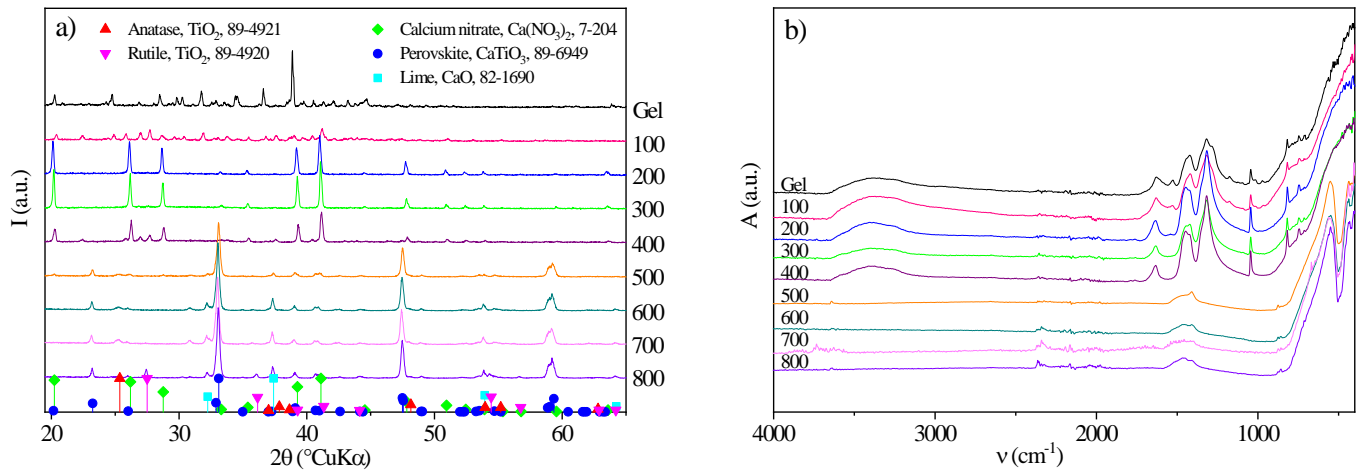

Figure 3. XRD patterns (a) and FTIR spectra (b) of the sample DP0 quenched from various temperatures.
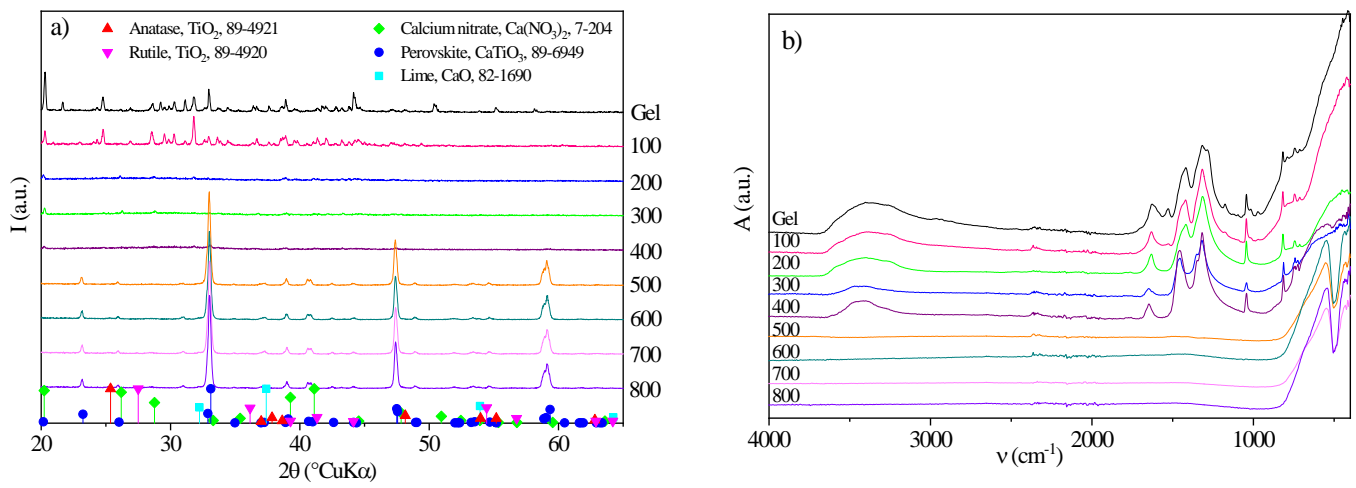

Figure 4. XRD patterns (a) and FTIR spectra (b) of the sample DP4 quenched from various temperatures.

XRD patterns of sample DP4 (Fig. 4a) are quite different from matching patterns of sample DP0. First of all, there are no peaks due to anhydrous calcium nitrate in the range of $200-400{ }^{\circ} \mathrm{C}$. Also, anatase or rutile peaks are absent and those due to lime are much weaker. However, although XRD patterns show no presence of nitrates in the sample DP4 quenched from various temperatures, FTIR spectra of the same samples (Fig. 4b) show nitrate bands pointing out to a presence of nitrates in amorphous form.

On the basis of XRD and FTIR investigations, the DTA/TGA results could be interpreted as follows: First three endothermal peaks with the corresponding mass loss could be attributed to the release of the remained solvent, 
water and decomposition of calcium nitrate tetrahydrate to anhydrous nitrate and water. Following exothermal peaks could be due to a redox process between nitrates and organics, as well as decomposition and burning of the chelate [1]. Combination of exothermal and endothermal peaks between 450 and $610{ }^{\circ} \mathrm{C}$ is due to the decomposition of nitrates, accompanied with mass loss and crystallization of the perovskite. The endothermal peak and mass loss in temperature interval between 700 and $800{ }^{\circ} \mathrm{C}$ could be interpreted as slow residual char oxidation process.

Since the XRD and FTIR results of quenched samples indicated that the perovskite phase appears between 400 and $500{ }^{\circ} \mathrm{C}$, sample DP0 was thermally treated at 400 and $500{ }^{\circ} \mathrm{C}$ for different time periods (Fig. 5). Samples thermally treated at $400{ }^{\circ} \mathrm{C}$ without holding and for 2 and 4 hours show less anatase and lime in comparison to the samples treated at $500{ }^{\circ} \mathrm{C}$. However, the amount of anatase and lime increases with time and samples show the presence of nitrates. Comparing the XRD pattern for the sample thermally treated at $500{ }^{\circ} \mathrm{C}$ without holding with the XRD pattern of the sample thermally treated at $500{ }^{\circ} \mathrm{C}$ for 2 hours, it can be observed that more lime was formed after 2 hours, while the amount of anatase is equal in both samples. In order to avoid the presence of nitrates in the samples, it was decided that all the samples will be thermally treated at $500^{\circ} \mathrm{C}$ for 2 hours.

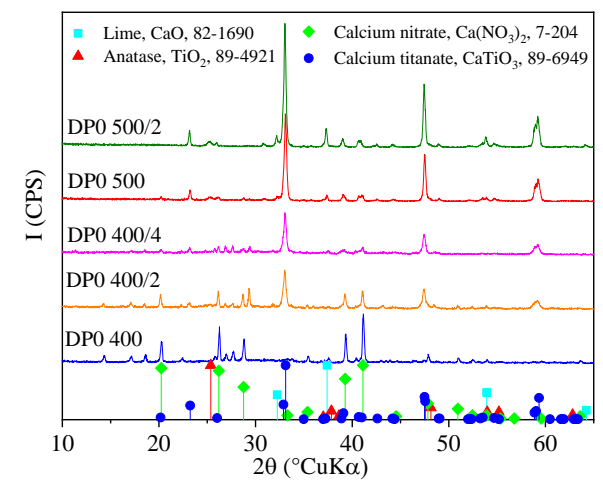

Figure 5. XRD patterns of the sample DP0 thermally treated at different temperatures and processing times.

XRD patterns of the samples thermally treated at $500{ }^{\circ} \mathrm{C}$ for $2 \mathrm{~h}$ (Fig. 6a) revealed that perovskite is the main crystalline phase in all samples. Along with perovskite, a small amount of $\mathrm{Ca}_{2} \mathrm{Ti}_{2} \mathrm{O}_{6}$, ICDD PDF No. 40-103, appears in all of the samples. Judging by the peak intensities, the amount of $\mathrm{Ca}_{2} \mathrm{Ti}_{2} \mathrm{O}_{6}$ is similar in all of the samples $\mathrm{Ca}_{2} \mathrm{Ti}_{2} \mathrm{O}_{6}$ has a pyrochlore structure which has many special properties and is researched for potential applications in luminescence, ionic conductivity, ferroelectricity, superconductivity, nuclear waste immobilization, high temperature thermal barrier coatings, automobile exhaust gas control, catalysts and solid oxide fuel cells [16]. The appearance of this valuable compound may be a subject of further research. In samples DP0, DP1, DP2 and possibly DP3, faint peaks due to lime and anatase could be observed. Those peaks diminish in intensity with the increase of a dopant amount. As evidenced by XRD pattern of sample DP4, no peaks of phases other than perovskite and $\mathrm{Ca}_{2} \mathrm{Ti}_{2} \mathrm{O}_{6}$ could be observed. No apparent peak positions shifts were noted, but since no standard was added, the discussion on dopants entering perovskite structure is pointless.

Figure $6 \mathrm{~b}$ shows FTIR spectra of the prepared samples after thermal treatment at $500^{\circ} \mathrm{C}$ for a period of 2 hours. The absorption bands at $430 \mathrm{~cm}^{-1}$ and $555 \mathrm{~cm}^{-1}$ are characteristic for the stretching of the Ti-O bond and the Ti-O$\mathrm{Ti}$ bond in the $\mathrm{TiO}_{6}$ octahedron of the formed perovskite [14]. Weak bands of the carboxyl group are seen at 1460 and $1410 \mathrm{~cm}^{-1}[15]$.
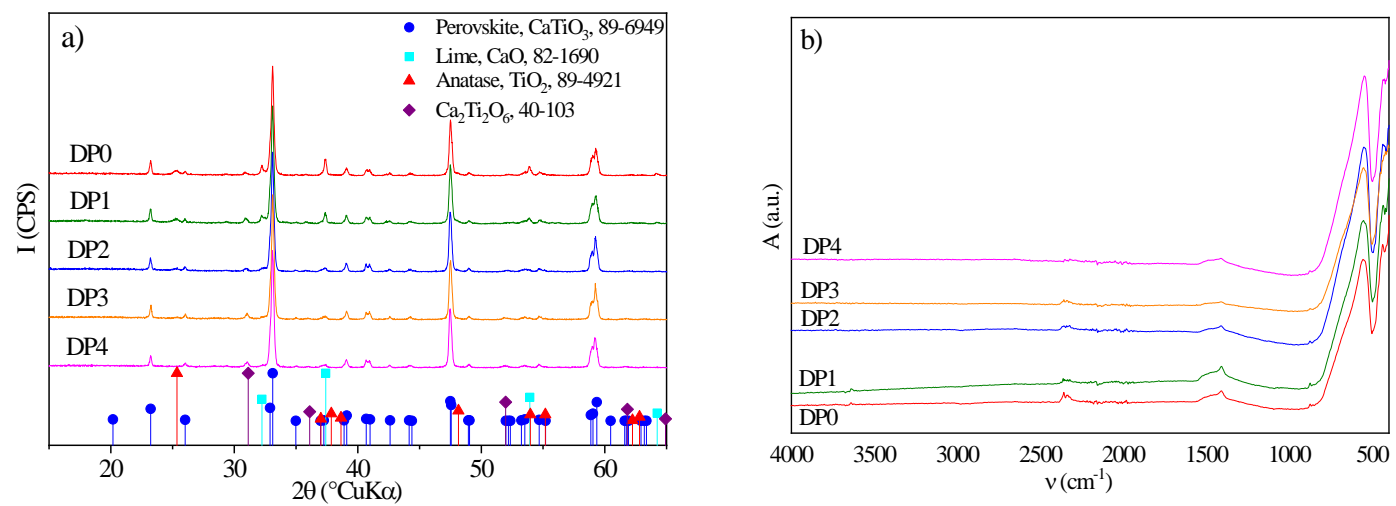

Figure 6. XRD patterns (a) and FTIR spectra (b) of the prepared samples thermally treated at $500{ }^{\circ} \mathrm{C}$ for $2 \mathrm{~h}$. 
Microstructures and morphologies of the samples DP0, DP2 and DP4 thermally treated at $500{ }^{\circ} \mathrm{C}$ for $2 \mathrm{~h}$ are shown in Fig. 7. It can be seen that samples are consisted of agglomerates of irregular morphology. It seems that primary particle sizes diminish with the increase of dopants concentration. Dominant particle size is far greater than $1 \mu \mathrm{m}$ for the non-doped sample, greater than $1 \mu \mathrm{m}$ for sample DP2 and below $1 \mu \mathrm{m}$ for sample DP4.
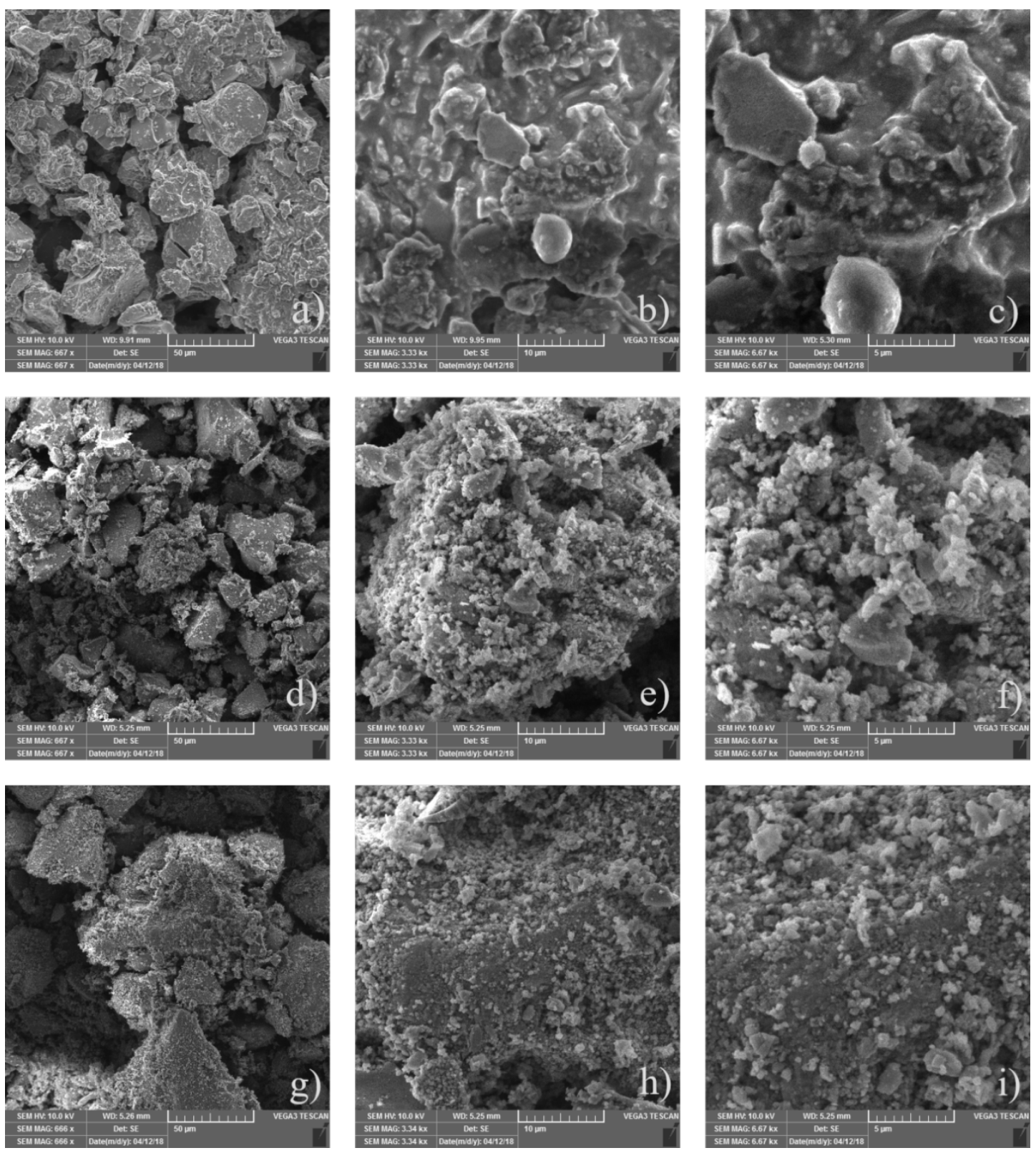

Figure 7. SEM micrographs of samples DP0 (a-c), DP2 (d-f) and DP4 (g-i) thermally treated at $500{ }^{\circ} \mathrm{C}$ for $2 \mathrm{~h}$.

EDS spectra of of samples DP0, DP2 and DP4 thermally treated at $500{ }^{\circ} \mathrm{C}$ for 2 h presented in Fig. 8 showed the presence of $\mathrm{Ca}$, Ti and $\mathrm{O}$, as well as $\mathrm{C}$, $\mathrm{Au}$ and $\mathrm{Pd}$. Ca, Ti and $\mathrm{O}$ are constituents of the perovskite, while the presence of $\mathrm{C}$ is due to the carbon conductive tape. Au and Pd are components of sputtered coating. It appears that the amounts of Li and Ce were not enough to give a clear signal, so doped elements couldn't be confirmed. Additionally, Li has very low energy of characteristic radiation, which is not easy to detect by used EDS detector.

The photocatalytic activities of the non-doped sample and sample with maximal amount of dopants were evaluated by monitoring the degradation of MB under UV irradiation. The degradation of MB without the presence of photocatalyst (wct) has been investigated for the purpose of comparison. Photocatalytic performance of the synthesized powders under UV light is shown in Fig. 9a. The decrease in MB concentration before switching on the UV lamp represents the amount of MB adsorbed on the surface of the photocatalyst. Higher adsorption is shown by the DP4 sample, probably due to a larger specific surface area in comparison to sample DP0, which can 
be substantiated by smaller particle size of the DP4 sample according to SEM measurements. In both the doped and non-doped sample temporal decrease of MB concentration can be observed.

It was found that the photocatalysis in presence of the non-doped sample is similar as the one without catalyst. However, loading of dopants yields with enhanced catalytic activity in sample DP4. The photodegradation efficiency reached $90 \%$ after $150 \mathrm{~min}$. In order to quantitatively describe MB photocatalytic degradation process, the pseudo-first-order kinetic function is usually used: $-\ln \left(\mathrm{c}_{t} / \mathrm{c}_{0}\right)=\mathrm{kt}$, where $\mathrm{c}_{0}$ is initial MB concentration, $\mathrm{C}_{t}$ is MB concentration after irradiation time $t$, and $k$ is the apparent first-order reaction constant. Fig. 9b shows dependences of $\mathrm{MB}-\ln \left(\mathrm{c}_{\mathrm{t}} / \mathrm{C}_{0}\right)$ values as a function of UV irradiation exposure. As can be observed, plots of $\ln \left(\mathrm{C}_{t} / \mathrm{C}_{0}\right)$ vs. $t$ exhibited a linear relationship proofing that photocatalytic degradation of MB obeys the pseudo first-order kinetics. The obtained reaction constants for MB degradation without photocatalyst and with DP0 photocatalyst are almost the same. On the other hand, reaction constant in the presence of DP4 photocatalyst is notably greater pointing out to a beneficial action of dopants. Increased photocatalytic activity could be related to greater specific surface area or decreased band gap energy, which will be the subject of future research.

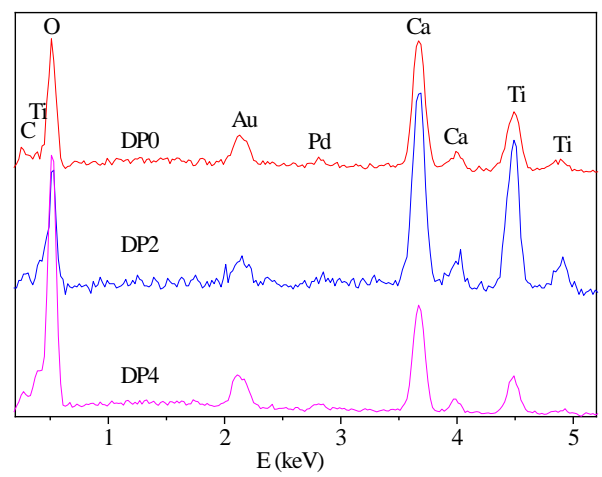

Figure 8. EDS spectra of samples DP0 (a-c in previous figure), DP2 (d-f) and DP4 (g-i) thermally treated at 500 ${ }^{\circ} \mathrm{C}$ for $2 \mathrm{~h}$.
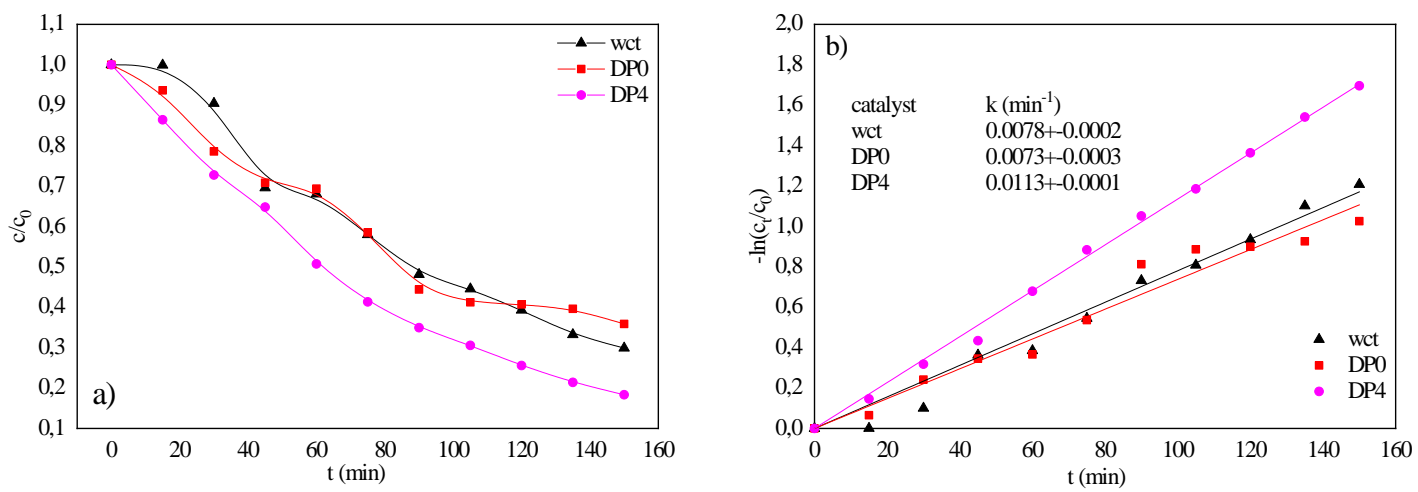

Figure 9. Photocatalytic activity of prepared powder samples under UV light (a) and dependence of $\mathrm{MB}-\ln \left(\mathrm{c} / \mathrm{c}_{0}\right)$ value as a function of UV irradiation exposure (b).

\section{Conclusion}

Samples of coded perovskite were prepared by sol-gel method. Combining DTA/TGA analysis, X-ray diffraction and FTIR spectroscopy, it was found that thermal treatment of the samples first led to the release of residual solvent and water from the samples. At elevated temperatures, the decomposition and burning of the chelate occur, and finally between $450{ }^{\circ} \mathrm{C}$ and $610^{\circ} \mathrm{C}$ the nitrate decomposes followed by the crystallization of the perovskite. In samples thermally treated at $500{ }^{\circ} \mathrm{C}$ for $2 \mathrm{~h}$, perovskite is the major crystalline phase. $\mathrm{Ca}_{2} \mathrm{Ti}_{2} \mathrm{O}_{6}$ is present in all samples, while anatas and lime are present in samples with lower dopant content. SEM micrographs showed that the particle size decreases with the increase of the dopant content. EDS spectra confirmed the presence of $\mathrm{Ca}$, Ti and O. Due to the small amount, it was not possible to confirm the presence of dopants in the samples. The photocatalytic activity of the non-doped sample and the sample with the maximum dopant concentration was evaluated by measuring the degradation of methylene blue under UV irradiation. The methylene blue degradation reaction constants without the photocatalyst and with the DP0 photocatalyst are almost identical. The reaction 
constant with the DP4 photocatalyst is noticeably higher. Increased photocatalytic activity can be attributed to a larger specific surface area or reduced band gap energy of the DP4 sample.

\section{Acknowledgement}

This work has been fully supported by Croatian Science Foundation under the project IP-01-2018-2963. The sustenance of the University of Zagreb is gratefully acknowledged.

\section{References}

[1] Hu Y, Mao L, Guan X, Tucker KA, Xie H, Wu X, Shi J. Layered perovskite oxides and their derivative nanosheets adopting different modification strategies towards better photocatalytic performance of water splitting. Renewable and Sustainable Energy Reviews. 2020;119:1-28.

[2] Pei J, Meng J, Wu S, Lin Q, Li J, Wei X, Han G, Zhang Z. Hierarchical $\mathrm{CaTiO}_{3}$ nanowire-network architectures for $\mathrm{H}_{2}$ evolution under visible-light irradiation. Journal of Alloys and Compounds. 2019;806:889-896.

[3] Haruna A, Abdulkadir I, Odris SO. Photocatalytic activity and doping effects of BiFeO3 nanoparticles in model organic dyes. Heliyon. 2020;6:1-28.

[4] Wang W, Tadé MO, Shao Z. Research progress of perovskite materials in photocatalysis- and photovoltaicsrelated energy conversion and environmental treatment. Chemical Society Review. 2015;44:1-38.

[5] O’Connel M, Norman AK, Hüttermann CF, Morris MA. Catalytic oxidation over lanthanum-transition metal perovskite materials. Catalysis Today. 1999;47:123-132.

[6] Wang M, Wang C, Liu Y, Zhou X. Hybrid density functional theory description of non-metal doping in perovskite $\mathrm{BaTiO}_{3}$ for visible-light photocatalysis. Journal of Solid State Chemistry. 2019;280:1-9.

[7] Richter J, Holtappels P, Graule T, Nakamura T, Gauckler LJ. Materials design for perovskite SOFC cathodes. Monatshefte für Chemie - Chemical Monthly. 2009;140:985-999.

[8] Gualdrón Reyes AF, Rodriguez-Pereira J, Amado-Gonzalez E, Rueda-P J, Ospina R, Masi S, Joon Yoon S, Tirado J, Jaramillo F, Agouram S, Munoz-Sanjose V, Gimenez S, Mora-Seró I. Unravelling the photocatalytic behavior of all-inorganic mixed halide perovskites: The role of surface chemical states. Applied Materials and Interfaces. 2019;12(1):914-924.

[9] Mehdizadeh P, Amiri O, Rashki S, Salavati-Niasari M, Salimian M, Kok Foong L. Effective removal of organic pollution by using sonochemical prepared LaFeO3 perovskite under visible light. Ultrasonics Sonochemistry. 2020;61:1-13.

[10] Shawky A, Alhaddad M, Al-Namshah KD, Mohamed RM, Awwad NS. Synthesis of Pt-decorated CaTiO 3 nanocrystals for efficient photoconversion of nitrobenzene to aniline under visible light. Journal of Molecular Liquids. 2020;304:1-8.

[11] Ficai D, Grumezescu AM. Nanostructures for novel therapy synthesis, characterization and applications. Elsevier. 2017.

[12] Kurajica S, Minga I, Mandić V, Matijašić G. Nanocrystalline anatase derived from modified alkoxide mesostructured gel. Journal of Thermal Analysis and Calorimetry. 2016;124:645-655.

[13] Kurajica S, Mandić V, Šipušić J. Thermal evolution of calcium aluminate gel. Journal of Ceramic Science Technology. 2011;2:15-22.

[14] Wang Y, Niu CG, Wang L, Wang Y, Zhang XG, Zeng GM. Synthesis of fern-like Ag/AgCl/CaTiO 3 plasmonic photocatalysts and their enhanced visible-light photocatalytic properties. RSC Advances. 2016;6:4787347882.

[15] Yang HK, Chung JW, Moon BK, Choi BC, Jeong JH, Kim JH, Kim KH. Enhanced luminescence properties of $\mathrm{Li}$-doped $\mathrm{CaTiO}_{3}: \mathrm{Pr}^{3+}$ thin films grown by PLD under various lithium ion contents. Current Applied Physics. 2011;11(3):S180-S183.

[16] Zhang Y, Yu J, Tu R, Goto T. Preparation of $\mathrm{Ca}_{2} \mathrm{Ti}_{2} \mathrm{O}_{6}$ pyrochlore films by MOCVD. Journal of Physics: Conference Series. 2009;152:1-7.

(C) 2020 by the author(s). This work is licensed under a Creative Commons Attribution 4.0 International License (http://creativecommons.org/licenses/by/4.0/). Authors retain copyright of their work, with first publication rights granted to Tech Reviews Ltd. 